\title{
Sensibilidad del cultivo de pool fecal para detectar infección por Mycobacterium avium subsp. paratuberculosis en rebaños bovinos de leche y su relación con la prueba de ELISA ${ }^{\#}$
}

\author{
Sensitivity of pooled faecal culture for detecting Mycobacterium avium subsp. paratuberculosis \\ infection in dairy herds and its relationship with the ELISA test
}

\author{
M Pradenas ${ }^{\mathrm{a}, \mathbf{b}^{*}}, \mathbf{J}$ Kruze $^{\mathrm{a}}$, G van Schaik ${ }^{\mathrm{c}, \mathrm{d}}$ \\ anstituto de Microbiología, Facultad de Ciencias. \\ bescuela de Graduados, Facultad de Ciencias Veterinarias. \\ 'Instituto de Medicina Preventiva Veterinaria, Facultad de Ciencias Veterinarias, Universidad Austral de Chile, Valdivia Chile. \\ dAnimal Health Service Ltd., Denveter. The Netherlands.
}

\begin{abstract}
SUMMARY
The aim of the present study was to evaluate the sensitivity and specificity of pooled faecal culture as a better alternative for the diagnosis of paratuberculosis in dairy herds compared to the conventional faecal culture and the ELISA test. Individual faecal and blood samples were collected from 50 cows in each one of 12 dairy herds $(n=598)$ with a history of paratuberculosis. Faecal samples were cultured on Herrold's medium individually and in pools of 5 and 10 animals strategically grouped according to age. Sensitivity and specificity of both tests were evaluated by means of two by two tables using the conventional faecal culture as the reference test. 10 (83.3\%) herds and 42 (7\%) animals resulted positive for Map, and 15.8\% and 22\% of pooled faecal samples ( 5 and 10 animals, respectively) were also positive. The sensitivity of the pooled faecal samples was $43.2 \%$ for the 5 animal pools and $46.4 \%$ for the 10 animal pools whilst the sensitivity of the ELISA test was $42.9 \%$. The cost of using pooled faecal culture in 5 animals was similar to that of the ELISA test but four times less than the conventional faecal culture; however, the sensitivity and specificity of this pool was similar to the conventional faecal culture. These results suggest that faecal culture with pooled samples could be successfully used in combination with ELISA test for detection of Map infection in dairy herds.
\end{abstract}

Palabras clave: paratuberculosis, cultivo fecal, pool fecal, ELISA

Key words: paratuberculosis, faecal culture, pooled samples, ELISA.

\section{INTRODUCCION}

La paratuberculosis bovina o Enfermedad de Johne es una enfermedad infecciosa causada por Mycobacterium avium subsp. paratuberculosis (Map), que afecta principalmente a rumiantes y se caracteriza por producir una enteritis crónica, disminución de la producción láctea, diarrea intermitente y enflaquecimiento progresivo que termina con la muerte del animal. Esta enfermedad, de distribución mundial, causa grandes pérdidas económicas en rebaños lecheros debido a una menor producción de leche y eliminación prematura de animales con pérdida de material genético (Hutchinson 1996, Van Schaik y col 1996). La enfermedad es considerada más que un problema individual, un problema de rebaño (Kalis y col 2000), y se caracteriza por presentar una baja prevalencia individual pero una alta prevalencia predial.

\footnotetext{
Aceptado: 24.05.2007.

\# Financiamiento: DID UACh Proyecto $N^{\circ}$ S-2003-40 y FAT/ CORFO.

* Casilla 167, Valdivia, Chile; mpradenas@uach.cl
}

En Chile no existen antecedentes oficiales de prevalencia de paratuberculosis a nivel nacional, sin embargo, Map ha sido aislado en numerosas oportunidades en rebaños bovinos del sur de Chile (Grinbergs y Caorsi 1958, Soto y col 2002 ab , Haro 2005, Pradenas 2006) y antecedentes no publicados hacen sospechar que existe una alta prevalencia predial.

Además la enfermedad también ha sido descrita en otras especies domésticas y silvestres (Zamora y col 1975, Kruze y col 2007, Salgado y col 2007, Paredes y col 2007).

La base del control de esta enfermedad es el correcto y oportuno diagnóstico de los animales infectados subclínicamente y su inmediata eliminación o segregación para evitar la transmisión de la infección a los animales más jóvenes, que son los más susceptibles. El diagnóstico de paratuberculosis en bovinos con signología clínica (edema submandibular, diarrea crónica y pérdida progresiva de peso) no es difícil; sin embargo, el diagnóstico de la enfermedad en animales infectados asintomáticos es extremadamente difícil, ya que no existe ningún método diagnóstico capaz de detectar a todos los animales infectados de un rebaño (Collins 2004). La mayoría de las pruebas diagnósticas actualmente disponibles se basan en la detección de la 
respuesta inmune humoral, y en la detección de Map en las heces a través del cultivo fecal o mediante la prueba molecular de PCR; sin embargo, estas pruebas no son capaces de detectar infección en animales en estadios iniciales de la enfermedad (Whitlock y col 2000).

El cultivo fecal, a pesar de tener baja sensibilidad (50\%), es el método más ampliamente usado para la detección del agente y es considerado como la "prueba de oro", con una especificidad superior al 99\%. Sin embargo, no es capaz de detectar animales que excretan Map por las deposiciones en cantidades inferiores a 100 ufc/g de heces (Collins 1996, Stabel 1997, Stabel 1998, Kalis 2001). El cultivo fecal presenta las desventajas de ser laborioso, de alto costo y extremadamente lento para entregar un resultado, ya que se requieren 8-16 semanas de incubación para detectar la presencia de colonias visibles (Sweeney y col 1995, Collins 1996, Kalis y col 1999, Soto y col 2002b).

La detección de anticuerpos anti-Map en el suero de animales infectados mediante la prueba de ELISA es actualmente el método de diagnóstico más ampliamente usado para el monitoreo de rebaños infectados ya que, contrariamente al cultivo fecal, es una prueba fácil de realizar, rápida y de bajo costo. Sin embargo, a pesar de tener una moderada especificidad (90-99\%) su sensibilidad promedio es baja (45\%), pudiendo alcanzar hasta $85 \%$ en animales con signos clínicos, pero no supera el $15 \%$ en animales con infección subclínica debido a que la respuesta inmune humoral se desarrolla tardíamente en los animales infectados (Cocito y col 1994, Collins 1996, Whitlock y Buergelt 1996, Stabel 1998). En consecuencia, la principal desventaja de las pruebas serológicas es que no permiten detectar infección en animales jóvenes cuando aún no desarrollan signos clínicos a pesar de excretar la bacteria por las deposiciones (Sockett y col 1992, Sweeney y col 1995).

En todo programa de control de paratuberculosis es recomendable el uso combinado de la prueba de ELISA y el cultivo fecal con el objeto de detectar el mayor número posible de animales infectados (Collins 2004). Sin embargo, el elevado costo del cultivo fecal no siempre permite el uso masivo del examen bacteriológico como herramienta diagnóstica. Investigaciones realizadas en los últimos años han demostrado que una alternativa diagnóstica de menor costo para detectar el agente en las heces es el cultivo de una mezcla de deposiciones de varios animales (pool fecal), alternativa que no afecta la sensibilidad ni especificidad del cultivo fecal convencional (Sweeney y col 1995, Collins 1996, Kalis y col 2000, Wells y col 2002). El cultivo de pool fecales permite examinar un gran número de animales en un rebaño a un menor costo, ya que sólo los pools positivos necesitan ser re-examinados individualmente para identificar los animales infectados.

El objetivo de este estudio fue comparar la sensibilidad del cultivo de pool fecal con el cultivo fecal individual y la prueba de ELISA con la finalidad de recomendar su uso en el diagnóstico y control de paratuberculosis bovina.

\section{MATERIAL Y METODOS}

\section{REBAÑOS LECHEROS}

Se seleccionaron 12 rebaños bovinos lecheros de la $\mathrm{X}$ Región (Chile), con antecedentes clínicos, histopatológicos o serológicos de paratuberculosis, basado en información previa obtenida directamente con los propietarios de los rebaños o con sus respectivos médicos veterinarios. Para cada rebaño se confeccionó una ficha con antecedentes generales de manejo del rebaño y edad o número de partos de los animales.

\section{MUESTRAS FECALES}

En cada uno de los rebaños seleccionados se recolectó un máximo de 50 muestras fecales individuales de vacas, preferentemente mayores de 3 partos. Las muestras fueron obtenidas por vía rectal utilizando mangas individuales desechables y transportadas al laboratorio en frascos estériles para coprocultivos de $50 \mathrm{~mL}$, debidamente rotulados. Las muestras fueron mantenidas a temperatura ambiente, y procesadas dentro de 24 horas de obtenidas cultivándose simultáneamente en forma individual y en pools de 5 y 10 animales. Para la confección de cada pool, los animales se agruparon estratégicamente de acuerdo a la fecha de nacimiento o al número de partos (10 pools de 5 vacas y 5 pools de 10 vacas por cada rebaño). Cada pool consistió de una suspensión homogénea de $2 \mathrm{~g}$ de heces por animal en $5 \mathrm{~mL}$ de agua desionisada estéril contenido en un tubo cónico estéril.

\section{CULTIVO FECAL}

Descontaminación de las muestras. Previo al cultivo las muestras fecales fueron descontaminadas de acuerdo al procedimiento recomendado por el Laboratorio de Diagnóstico de la Universidad de Cornell, USA (Shin y col 1990), transfiriendo $2 \mathrm{~g}$ de cada muestra, tanto individual como pool, a un tubo cónico de centrífuga de $50 \mathrm{~mL}$ de capacidad conteniendo $35 \mathrm{~mL}$ de agua desionisada estéril, se agitaron en posición horizontal durante 30 minutos en un agitador orbital y luego se dejaron reposar en posición vertical durante 30 minutos a temperatura ambiente. Posteriormente, $5 \mathrm{ml}$ del sobrenadante de cada tubo fue transferido a un nuevo tubo estéril conteniendo $25 \mathrm{~mL}$ de HPC (solución al 0,9\% de cloruro de hexadecilpiridinio, SIGMA), los cuales fueron incubados a $37{ }^{\circ} \mathrm{C}$ durante 16-24 horas; posteriormente las muestras se centrifugaron a $1700 \mathrm{x}$ g durante 20 minutos a $15^{\circ} \mathrm{C}$, se eliminó el sobrenadante y el pellet se resuspendió en $1 \mathrm{~mL}$ de una solución antibiótica compuesta por $100 \mu \mathrm{g} / \mathrm{ml}$ de ácido nalidíxico, $100 \mu \mathrm{g} / \mathrm{mL}$ de vancomicina y $50 \mu \mathrm{g} / \mathrm{mL}$ amfotericina $\mathrm{B}$, dejándose actuar por 24 horas a $37{ }^{\circ} \mathrm{C}$. Esta suspensión se utilizó para inocular todos los medios de cultivo. 
Medio de cultivo. Se utilizó el medio de Herrold modificado con yema de huevo (HEYM) y micobactina J (Allied Monitor, Inc., USA) en tubos de agar inclinado con tapa rosca, preparado de acuerdo a las recomendaciones del Laboratorio de Diagnóstico de la Universidad de Cornell, USA (Shin y col 1990), utilizando huevos frescos SPF producidos en el Instituto de Patología Animal, Facultad de Ciencias Veterinarias, Universidad Austral de Chile.

Inoculación e incubación de las muestras. Cada muestra fecal, individual y pool, fue sembrada simultáneamente en 3 tubos HEYM con micobactina J y 1 tubo HEYM sin micobactina J, utilizando como inóculo $150 \mu \mathrm{L}$ de la suspensión fecal previamente descontaminada con HPC y antibióticos. La incubación de los tubos se realizó a $37^{\circ} \mathrm{C}$ en condiciones de aerobiosis manteniendo los tubos en posición horizontal y con las tapas sueltas durante la primera semana de incubación, para permitir una adecuada evaporación de la humedad en la superficie del medio; posteriormente los tubos se cerraron herméticamente para continuar la incubación en posición vertical hasta completar 16 semanas. Los tubos fueron examinados semanalmente para verificar el desarrollo de colonias y la eventual presencia de organismos contaminantes.

Lectura e interpretación de resultados. El desarrollo de colonias típicas de Map, después de 3 semanas de incubación en los tubos HEYM con micobactina pero sin desarrollo en los tubos HEYM sin micobactina, se consideró presuntamente positivo de Map. Para validar una muestra presuntamente positiva, al menos uno de los tres tubos inoculados por muestra debía estar libre de microorganismos contaminantes (Kalis y col 2000). Para confirmar una muestra presuntamente positiva, las colonias de los tubos positivos fueron sometidas a análisis molecular mediante la técnica de reacción de polimerasa en cadena (PCR), para detectar la presencia del elemento de inserción IS900, característico de Map (Laboratorio de Patología Molecular, Instituto de Bioquímica, Facultad de Ciencias, Universidad Austral de Chile.).

Los animales cuyas muestras fecales resultaron positivas al cultivo fecal fueron clasificados en cuatro categorías según el número de colonias (ufc/g) obtenidas en los tubos positivos: a) animales negativos (sin desarrollo de colonias), b) animales bajos eliminadores ( $<50 \mathrm{ufc} / \mathrm{g})$, c) animales moderados eliminadores (50-300 ufc/g), y d) animales altos eliminadores ( $>300 \mathrm{ufc} / \mathrm{g}$ ). El recuento de colonias no se consideró relevante para determinar el estatus de infección de un rebaño, ya que bastó un animal cultivo positivo, individual o pool, para clasificarlo como rebaño infectado (Kalis y col 2000).

\section{EXAMEN SEROLOGICO}

Obtención de muestras. Simultáneamente con la recolección de las muestras fecales se obtuvo una muestra de sangre de los mismos animales por punción de la vena coccígea utilizando tubos vacutainer estériles. Una vez en el laboratorio, se separó el suero y se congeló a $-20^{\circ} \mathrm{C}$ hasta su posterior procesamiento.

Prueba de ELISA. Para la detección de anticuerpos séricos contra Map se utilizó un kit comercial de ELISA (IDEXX Laboratories, Inc. USA). La medición y registro de la absorbancia o densidad óptica (DO) se realizó utilizando un lector de ELISA (BIOTEC ELX 800) con una longitud de onda de $620 \mathrm{~nm}$. La presencia o ausencia de anticuerpos anti-Map se determinó calculando la razón DO muestra problema/control positivo (M/P) para cada muestra, la que se basa en la densidad óptica del suero problema corregida de acuerdo a las densidades ópticas de los sueros controles positivos y negativos. Para que el ensayo sea considerado válido, la diferencia entre la media del control positivo y la media del control negativo debió ser mayor o igual a 0,150 ; además, la media del control negativo debió ser menor o igual a 2,20. La interpretación de los resultados se realizó de acuerdo a los valores de puntos de corte indicados por el fabricante, donde un animal con un valor M/P mayor a 0,25 fue considerado positivo.

Definición de caso. Para la determinación de la sensibilidad (SE) y especificidad (SP) de las diferentes pruebas diagnósticas, se consideró como animal infectado aquél con resultado positivo al cultivo fecal individual y como animal no infectado aquél con resultado negativo al cultivo fecal individual. Un pool fecal fue considerado positivo cuando se logró aislar Map en alguno de los 3 tubos inoculados. La SE de rebaño fue definida como la habilidad de la prueba para detectar, al menos, un animal infectado en un rebaño infectado, y la SE del pool se definió como la habilidad para detectar, al menos, un animal positivo.

Análisis estadístico. Para el cálculo de la sensibilidad de los pools y de la prueba de ELISA respecto de los cultivos fecales individuales, se utilizaron tablas de 2 entradas (Programa Win Episcope 2.0) y para verificar si existía diferencia entre las sensibilidades de los pools de 5 y 10 animales se utilizó la prueba exacta de Fisher en el programa Statistix 8.0.

\section{RESULTADOS}

Cultivo de muestras fecales. La utilización del medio de Herrold modificado con yema de huevo (HEYM) permitió aislar Map en $10(83,3 \%)$ de los 12 rebaños muestreados y en $42(7 \%)$ de las 598 muestras fecales individuales examinadas; la frecuencia de animales positivos al cultivo en los diferentes rebaños varió entre 2\% y $20 \%$ (cuadro 1 ).

Aunque fue posible aislar Map en animales con un amplio rango de edades (2-11 años), el mayor número de animales infectados correspondió al grupo de edades de 2 a 5 años; sin embargo, el mayor porcentaje de animales 
infectados estuvo en el grupo de animales $>5$ años con un $8,9 \%$ (12) de animales positivos al cultivo fecal individual (cuadro 2). El cultivo de los pools fecales permitió aislar Map en 19 (15,8\%) y $13(22 \%)$ de los 120 pools de 5 y los 60 pools de 10 animales, respectivamente.

Sensibilidad del pool fecal. Para determinar la sensibilidad de los pools fecales se utilizó como referencia los resultados de los cultivos fecales individuales, asumiendo una sensibilidad del 50\% para el cultivo fecal individual. Las sensibilidad promedio para los pools de 5 animales fue de 43,2\% (IC $23,8 \%-56,2 \%$ ) y la correspondiente a los pools de 10 animales fue de 46,4\% (IC 28,0\%-65,0\%) (cuadro 3).

Sensibilidad y especificidad de la prueba de ELISA. De las 42 muestras positivas al cultivo fecal individual sólo

Cuadro 1. Número y porcentaje de muestras fecales individuales positivas a Mycobacterium avium subsp. paratuberculosis en 12 rebaños lecheros.

Number and percentage of individual faecal samples positive to Mycobacterium avium subsp. paratuberculosis in 12 dairy herds.

\begin{tabular}{cccc}
\hline \multirow{2}{*}{ Rebaño } & \multirow{2}{*}{$\begin{array}{c}\text { No animales } \\
\text { muestreados }\end{array}$} & \multicolumn{2}{c}{ Cultivos fecales positivos } \\
\cline { 3 - 4 } & 50 & 5 & $\mathrm{~N}^{\mathbf{0}}$ \\
\hline 1 & 50 & 10 & 10 \\
2 & 50 & 2 & 20 \\
3 & 50 & 1 & 4 \\
4 & 50 & 1 & 2 \\
5 & 50 & 2 & 2 \\
6 & 50 & 6 & 4 \\
7 & 50 & 4 & 12 \\
8 & 50 & 10 & 8 \\
9 & 50 & 1 & 20 \\
10 & 48 & 0 & 2 \\
11 & 50 & 0 & 0 \\
12 & 598 & 42 & 7 \\
Total & & & 0 \\
\hline
\end{tabular}

Cuadro 2. Número y porcentaje de animales positivos al cultivo fecal de acuerdo a grupos de edades.

Number and percentage of animals positive to faecal culture according to age groups.

\begin{tabular}{|c|c|c|c|c|}
\hline \multirow{2}{*}{$\begin{array}{l}\text { Edad en } \\
\text { años }\end{array}$} & \multirow{2}{*}{$\begin{array}{l}\mathrm{N}^{\mathrm{o}} \text { de animales } \\
\text { muestreados }\end{array}$} & \multicolumn{3}{|c|}{$\begin{array}{l}\text { Cultivo fecal } \\
\text { positivo }\end{array}$} \\
\hline & & $\mathrm{N}^{\mathrm{o}}$ & $\%$ & $\mathrm{IC}^{*}$ \\
\hline$<2$ & 33 & 2 & 6,1 & $0-16$ \\
\hline $2-5$ & 430 & 28 & 6,5 & $4-9$ \\
\hline$>5$ & 135 & 12 & 8,9 & 4-14 \\
\hline Total & 598 & 42 & 7,0 & \\
\hline
\end{tabular}

IC: Intervalo de confianza 95\%.
18 resultaron positivas a la prueba de ELISA, es decir, el examen serológico fue capaz de detectar sólo el 42,9\% de los animales positivos (cuadro 4). El cálculo de la sensibilidad y la especificidad de la prueba de ELISA por rebaño demostró que en 3 de ellos la sensibilidad fue de $100 \%$, mientras que en 5 rebaños fue de $0 \%$. La especificidad en cambio, varió entre $87 \%$ y $100 \%$ (cuadro 5). La sensibilidad de la prueba de ELISA, según el estatus eliminador de Map de los animales cultivo positivo, demostró que a medida que aumenta el estatus eliminador de bacterias de los animales mejora la sensibilidad de la prueba alcanzando al $100 \%$ en el grupo de altos eliminadores (cuadro 6).

Cuadro 3. Número, porcentaje y sensibilidad promedio (SE) de pools fecales de 5 y 10 animales positivos a Mycobacterium avium subsp. paratuberculosis.

Number, percentage and average sensitivity of faecal pooled samples of 5 and 10 animals positive to Mycobacterium avium subsp. paratuberculosis.

\begin{tabular}{ccccc}
\hline \multirow{2}{*}{ Rebaño } & \multicolumn{4}{c}{ Cultivos fecales positivos } \\
\cline { 2 - 5 } & \multicolumn{1}{c}{ Pools de 5 animales } & \multicolumn{1}{c}{ Pools de 10 animales } \\
\cline { 2 - 5 } $\mathrm{N}^{\mathrm{o}}$ & $\%$ & $\mathrm{~N}^{\mathrm{o}}$ & $\%$ \\
\hline 1 & $6 / 10$ & $60 \%$ & $4 / 5$ & $80 \%$ \\
2 & $6 / 10$ & $60 \%$ & $5 / 5$ & $100 \%$ \\
3 & $0 / 10$ & $0 \%$ & $1 / 5$ & $20 \%$ \\
4 & $0 / 10$ & $0 \%$ & $0 / 5$ & $0 \%$ \\
5 & $0 / 10$ & $0 \%$ & $0 / 5$ & $0 \%$ \\
6 & $0 / 10$ & $0 \%$ & $0 / 5$ & $0 \%$ \\
7 & $3 / 10$ & $30 \%$ & $1 / 5$ & $20 \%$ \\
8 & $3 / 10$ & $30 \%$ & $0 / 5$ & $0 \%$ \\
9 & $1 / 10$ & $10 \%$ & $2 / 5$ & $40 \%$ \\
10 & $0 / 10$ & $0 \%$ & $0 / 5$ & $0 \%$ \\
11 & $0 / 10$ & $0 \%$ & $0 / 5$ & $0 \%$ \\
12 & $0 / 10$ & $0 \%$ & $0 / 5$ & $0 \%$ \\
Total & $19 / 120$ & $15,8 \%$ & $13 / 60$ & $22 \%$ \\
SE promedio & & $43,2 \%$ & & $46,4 \%$ \\
\hline
\end{tabular}

Cuadro 4. Cálculo de la sensibilidad y especificidad de la prueba de ELISA en relación a los cultivos fecales individuales.

Calculation of the sensitivity and specificity of the ELISA test in relation to the individual faecal samples.

\begin{tabular}{lccc}
\hline ELISA & $\begin{array}{c}\text { Cultivo } \\
\text { Positivo }\end{array}$ & $\begin{array}{c}\text { Cultivo } \\
\text { Negativo }\end{array}$ & Total \\
\hline Positivo & 18 & 28 & 46 \\
Negativo & 24 & 528 & 552 \\
Total & 42 & 556 & 598 \\
\hline
\end{tabular}

Sensibilidad: $18 /(18+24) \times 100=42,9 \%$.

Intervalo de confianza de la sensibilidad (95\%): $28,0 \%-58,0 \%$. Especificidad: $528 /(28+528) \times 100=95 \%$.

Intervalo de confianza de la especificidad (95\%): 93,1\% - 96,8\%. 
Cuadro 5. Sensibilidad (SE) y especificidad (SP) de la prueba de ELISA en relación a los cultivos fecales individuales según rebaño.

Sensitivity (SE) and specificity (SP) of the ELISA test in relation to individual faecal cultures according to herds.

\begin{tabular}{crr}
\hline Rebaño & SE & SP \\
\hline 1 & $80 \%$ & $100 \%$ \\
2 & $50 \%$ & $95 \%$ \\
3 & $100 \%$ & $100 \%$ \\
4 & $100 \%$ & $98 \%$ \\
5 & $0 \%$ & $100 \%$ \\
6 & $0 \%$ & $98 \%$ \\
7 & $20 \%$ & $93 \%$ \\
8 & $75 \%$ & $98 \%$ \\
9 & $0 \%$ & $93 \%$ \\
10 & $100 \%$ & $87 \%$ \\
11 & $0 \%$ & $94 \%$ \\
12 & $0 \%$ & $90 \%$ \\
\hline
\end{tabular}

Cuadro 6. Sensibilidad de la prueba de ELISA según estatus eliminador de los animales cultivo positivo.

Sensitivity of the ELISA test according to shedding status of culture positive animals.

\begin{tabular}{lcccc}
\hline \multirow{2}{*}{ Estatus eliminador (ufc/g) } & \multicolumn{4}{c}{ Prueba de ELISA } \\
\cline { 2 - 5 } & + & - & Total & SE \\
\hline Bajo (< a 50) & 12 & 24 & 36 & $33 \%$ \\
Medio (50 - 300) & 1 & 1 & 2 & $50 \%$ \\
Alto (> a 300) & 4 & 0 & 4 & $100 \%$ \\
Total & 17 & 25 & 42 & \\
\hline
\end{tabular}

\section{DISCUSION}

El control de la paratuberculosis en un rebaño infectado es un desafío difícil y de largo plazo, debiendo focalizarse básicamente en estrategias efectivas de manejo y diagnóstico a nivel de rebaño (Wells y col 2002, Collins 2004). Este aspecto es crítico porque, ya sea por razones económicas o por no definir claramente cuál es el objetivo de realizar el diagnóstico, muchas veces, la prueba de elección no es la más apropiada.

El aislamiento de Mycobacterium avium subsp. paratuberculosis en $10(83,3 \%)$ de los rebaños en estudio y en 42 (7\%) de los animales examinados permitió confirmar que este patógeno está presente en los rebaños lecheros del sur de Chile. Considerando que la sensibilidad del cultivo fecal no supera el $50 \%$, y que existen factores relacionados a la patogenia de la enfermedad como excreción intermitente del agente y la condición eliminadora del animal (bajo, moderado o alto eliminador), el porcentaje de animales realmente infectados en los rebaños es, probablemente, mayor al encontrado en este estudio. Por otra parte, en dos de los rebaños en estudio no fue posible aislar la bacteria y en tres de ellos se logró aislar Map solamente en un animal (cuadro 1). Considerando que en estos rebaños se encontraron animales positivos a la prueba de ELISA, y tomando en cuenta los factores anteriormente mencionados, es posible asumir que en estos rebaños existen animales infectados que no fueron detectados por el cultivo fecal (Collins 1996, Whitlock y Buergelt 1996, Stabel 1998).

$\mathrm{Al}$ analizar la población de animales cultivo positivo según rangos de edades (cuadro 2) no se encontraron diferencias significativas entre los grupos etarios; sin embargo, el mayor porcentaje $(8,9 \%)$ estuvo en el rango de animales mayores de 5 años, lo que concuerda con la patogenia de la enfermedad que se caracteriza por presentar un largo periodo de incubación con desarrollo de signos clínicos y excreción abundante de Map por las heces a edades más avanzadas (Whitlock y Buergelt 1996, Kalis y col 1999, Van Schaik y col 2005).

El cultivo de pools fecales demostró ser eficiente para diagnosticar infección permitiendo detectar animales infectados tanto en pools de 5 como de 10 animales $(15,8 \%$ y $22 \%$ de cultivos positivos, respectivamente), constituyendo una herramienta diagnóstica útil para clasificar a un rebaño como infectado. El uso de pools estratégicos de acuerdo a la edad de los animales hace más eficiente su uso, ya que disminuye la probabilidad de incluir un animal infectado eliminador de bacterias en un pool donde hay animales no infectados provocando un efecto de dilución (mezcla de heces infectadas con heces no infectadas en un mismo pool), lo que trae como consecuencia una disminución de la sensibilidad del pool (Kalis y col 2000). En este estudio, a pesar de la utilización de pools estratégicos de acuerdo a la edad de los animales, se presentaron casos en los que se observó este efecto de dilución, principalmente en los pools de 5 animales; en efecto, algunos de estos pools resultaron negativos al cultivo a pesar que una o más de las muestras individuales que conformaban dicho pool fueron positivas. Esto ocurrió principalmente con animales bajos eliminadores de Map (<50 ufc/g). En algunos pools de 10 animales se produjo un efecto inverso, es decir, algunos pools que fueron positivos a Map estaban conformados por muestras que resultaron todas negativas al cultivo fecal individual, situación que también ha sido descrita por otros investigadores (Wells y col 2002, Tavornpanich y col 2004), y que podría deberse a la presencia de animales bajos eliminadores con un nivel de excreción fecal que el cultivo individual no es capaz de detectar $(<100 \mathrm{ufc} / \mathrm{g})$ (Collins 1996).

Generalmente se describe que los pools de 5 animales son más sensibles que los pools de 10 animales para detectar infección por Map (Kalis y col 2000, Wells y col 2002, Wells y col 2003), sin embargo, en este estudio la sensibilidad obtenida para los pools de 5 animales fue de 43,2\% y para los pools de 10 animales 46,4\% (cuadro 3). La mayor sensibilidad de los pools de 10 animales podría 
deberse a que al aumentar el número de animales por pool aumenta la probabilidad de detección de la bacteria; otra explicación podría ser una inadecuada homogeneización de la muestra fecal durante el procesamiento para el cultivo, ya que en ocasiones es difícil romper un conglomerado bacteriano y distribuir homogéneamente la bacteria en toda la muestra fecal, o simplemente puede deberse a un efecto de azar de encontrar o no un conglomerado bacteriano en la muestra analizada (Kalis y col 2000, Wells y col 2002).

La sensibilidad del cultivo fecal está directamente relacionada con la prevalencia de infección presente en el rebaño y con la proporción de animales bajos, medios y altos eliminadores (Van Schaik y col 2005). Para el caso de los pools, aunque esta relación no ha sido descrita, los animales que eliminan más de $300 \mathrm{ufc/g}$ y forman parte de un pool, tienen una mayor probabilidad de ser detectados en un pool fecal a diferencia de los animales bajos o medianos eliminadores, donde la probabilidad de detección es menor debido al efecto de dilución mencionado anteriormente. Al determinar la sensibilidad de los pools de 5 animales en relación a la prevalencia predial de infección, sólo se observó diferencia significativa entre los rebaños de baja prevalencia y los de mediana y alta prevalencia, resultado que era obvio de esperar ya que en los rebaños de baja prevalencia se encontraron animales bajos eliminadores a diferencia de los rebaños de media y alta prevalencia en los cuales la mayoría de los animales eran medios y altos eliminadores.

Está demostrado que a medida que la enfermedad progresa aumenta la concentración de anticuerpos circulantes y la tasa de eliminación de bacterias por las heces; en consecuencia a medida que la infección avanza, es más fácil detectar animales infectados a través de la prueba de ELISA como también a través del cultivo fecal (Whitlock y col 2000). Esto explica por qué la sensibilidad promedio de la prueba de ELISA es sólo de un $15 \%$ en animales subclínicos y de un $85 \%$ en animales con signos clínicos, con una sensibilidad promedio de 45\% (Cocito y col 1994, Collins 1996, Whitlock y Buergelt 1996, Stabel 1998).

La sensibilidad promedio obtenida en este estudio para la prueba de ELISA considerando todos los rebaños fue $42,9 \%$ (cuadro 4), valor que se encuentra dentro del promedio descrito para la prueba; sin embargo, al calcular la sensibilidad individualmente por rebaño (cuadro 5), se puede observar que en 5 de ellos la sensibilidad fue $0 \%$, debido probablemente a que en estos rebaños los animales se encontraban en estados iniciales de la infección (Whitlock y col 2000). Al comparar la sensibilidad de la prueba de ELISA según el grado eliminador de los animales $(33 \%, 50 \%$ y $100 \%$ para bajos, medios y altos eliminadores, respectivamente) (cuadro 6), se observó una tendencia similar a lo descrito por otros autores, donde se reporta un $15 \%$ de sensibilidad para animales subclínicos, un $70 \%$ para animales enfermos con moderada eliminación de bacterias por las heces y un $87 \%$ para animales clínicamente enfermos que eliminan grandes cantidades de bacterias por las heces (Dargatz y col 2001).

Una de las principales ventajas de detectar rebaños infectados a través del cultivo de pools fecales, como alternativa al cultivo fecal individual, es que una mayor cantidad de animales pueden ser examinados en un pool por los mismos costos fijos de laboratorio. De esta forma, si un productor desea limitar sus costos de laboratorio manteniendo la sensibilidad y especificidad del cultivo fecal, la alternativa de realizar pools sobre el tamaño total de la población es ventajosa, ya que aumenta la sensibilidad predial al aumentar el número de animales muestreados (Christensen y Gardner 2000).

En los rebaños de baja prevalencia, al no existir pools positivos, se asume que todos los animales pertenecientes a dicho pool son negativos y, por lo tanto, no se generan costos adicionales por repetir cultivos individuales en un segundo muestreo. En cambio, en rebaños de alta prevalencia (>10\%), la probabilidad de que la mayoría de los pools den un resultado positivo es alta, por lo que no se recomienda el uso de pools fecales como método de diagnóstico en este tipo de rebaños (Van Schaik y col 2003, 2007).

Una publicación reciente de un grupo de expertos internacionales en diagnóstico de paratuberculosis (Collins y col 2006) recomienda en forma consensuada el uso de las diferentes pruebas diagnósticas, según sea el objetivo del diagnóstico: clasificación de rebaños en infectados y no infectados, estimación de prevalencia individual, control de la enfermedad, monitoreo, erradicación de la enfermedad, confirmación de casos clínicos, y prevención del ingreso de la infección en un rebaño libre. Considerando que el diagnóstico de paratuberculosis tiene un fuerte impacto económico, especialmente en rebaños con un gran número de animales, el uso del cultivo de pool fecal es la mejor y menos costosa alternativa para clasificar a un rebaño como infectado o no infectado, principalmente en rebaños de media y baja prevalencia, con una sensibilidad y especificidad similar al cultivo fecal individual, pero a un considerable menor costo.

Por otra parte, el mayor impacto económico con consecuencias negativas en un rebaño está dado por los animales en estadios tardíos de la enfermedad (altos eliminadores y fuertemente positivos a la prueba de ELISA) (Lombard y col 2005), por lo que el cultivo de pools fecales se podría recomendar en forma combinada con la prueba de ELISA en los programas de control de paratuberculosis bovina.

\section{RESUMEN}

El objetivo del presente estudio fue evaluar la sensibilidad y especificidad del cultivo de pool fecal como alternativa diagnóstica de paratuberculosis en rebaños lecheros bovinos comparado con el cultivo fecal individual y la prueba de ELISA con la finalidad de reducir costos asociados al diagnóstico de la enfermedad. En 12 rebaños lecheros con antecedentes de paratuberculosis se recolectó un máximo de 50 muestras fecales individuales por rebaño $(n=598)$ y se cultivaron en medio de Herrold en forma individual y en pools estratégicos de 5 y 10 animales. 
Simultáneamente, de cada animal se recolectó una muestra de sangre para la prueba de ELISA. Se evaluó la sensibilidad y especificidad de las pruebas usando como referencia los cultivos fecales individuales mediante tablas de dos entradas. En $10(83,3 \%)$ rebaños y en $42(7 \%)$ animales fue posible aislar Map en tanto que el $15,8 \%$ y $22 \%$ de los pools de 5 y 10 animales, respectivamente, resultaron positivos al cultivo fecal. La sensibilidad de los pools fecales de 5 y 10 animales fue $43,2 \%$ y $46,4 \%$, respectivamente, mientras que la sensibilidad del ELISA fue 42,9\%. El costo de los pools fecales de 5 animales fue similar al de la prueba de ELISA, pero cuatro veces menor que el costo del cultivo fecal individual; sin embargo, la sensibilidad y especificidad de los pools de 5 animales fue similar a los cultivos individuales. El cultivo de pools fecales demostró ser una buena y costo-efectiva alternativa para el diagnóstico de paratuberculosis para detectar rebaños infectados con Map.

\section{REFERENCIAS}

Christensen J, IA Gardner. 2000. Herd-level interpretation of test results for epidemiologic studies of animal diseases. Prev Vet Med $45,83-106$.

Cocito C, P Gilot, M Coene, M Kesel, P Pouspart, P Vannufel. 1994. Paratuberculosis. Clin Microbiol Rev 7, 328-344.

Collins MT. 1996. Diagnosis of paratuberculosis. Vet Clin North Am Food Anim Pract 12, 357-371.

Collins MT. 2004. Update on paratuberculosis: control and zoonotic potential. Irish Vet J 57, 49-52.

Collins MT, IA Gardner, FB Garry, AJ Roussel, SJ Wells. 2006. Consensus recommendations on diagnostic testing for the detection of paratuberculosis in cattle in the United States. J Am Vet Med Ass 229, 1912-1919.

Dargatz DA, BA Byrum, LK Barber, RW Sweeney, RH Withlock, WP Shulaw, RH Jacobson, JR Stabel. 2001. Evaluation of a commercial ELISA for diagnosis of paratuberculosis in cattle. Am J Vet Ass 218, 1163-1166.

Grinbergs J, I Caorsi. 1958. Enfermedad de Johne o paratuberculosis en Chile. Publicaciones Científicas de la Universidad Austral de Chile 4, 9-13.

Haro FH. 2005. Validación de una prueba de ELISA para detectar infección por Mycobacterium avium subsp. paratuberculosis en rebaños lecheros del sur de Chile. Tesis de Magíster, Facultad de Ciencias Veterinarias, Universidad Austral de Chile, Valdivia, Chile.

Hutchinson LL. 1996. Economic impact of paratuberculosis. Vet Clin North Am Food Anim Pract 12, 373-383.

Kalis CHJ, JW Hesselink, H Russchen, HW Barkema, MT Collins, IJR Visser. 1999. Factors influencing the isolation of Mycobacterium avium subsp. paratuberculosis from bovine fecal samples. $J$ Vet Diagn Invest 11, 345-351.

Kalis CHJ, JW Hesselink, HW Barkema, MT Collins. 2000. Culture of strategically pooled bovine fecal samples as a method to screen herds for paratuberculosis. J Vet Diagn Invest 12, 547-551.

Kalis K. 2001. Diagnosis of paratuberculosis. In: On- Farm Control and Diagnosis of Paratuberculosis. Bull Intern Dairy Fed, Pp 14-28.

Kruze J, M Salgado, MT Collins. 2007. Paratuberculosis en rebaños caprinos chilenos. Arch Med Vet 39,147-152.

Lombard JE, FB Garry, BJ McCluskey, BA Wagner. 2005. Risk of removal and effects on milk production associated with paratuberculosis status in dairy cows. J Am Vet Med Ass 227, 1975-1981.

Paredes E, M Pradenas, MC Jara, MT Collins, J Kruze. 2007. Pathological and bacteriological diagnosis of paratuberculosis in farmed red deer (Cervus elaphus) and fallow deer (Dama dama) in Chile. Proceedings $9^{\text {th }}$ International Colloquium on paratuberculosis, Tsukuba, Japan.

Pradenas M. 2006. Eficacia del cultivo de pool fecal para detectar infección por Mycobacterium avium subsp. paratuberculosis en rebaños lecheros. Tesis de Magíster, Facultad de Ciencias Veterinarias, Universidad Austral de Chile, Valdivia, Chile.
Salgado M, D Herthneck, G Bölske, J Kruze. 2007. Isolation and molecular confirmation of Mycobacterium avium subsp. paratuberculosis in guanacos (Lama guanicoe) in Tierra del Fuego, Chile, by fecal culture and Real-Time PCR. Proceedings $9^{\text {th }}$ International Colloquium on paratuberculosis, Tsukuba, Japan.

Shin SJ, V Patten, DH Lein. 1990. New Cornell methods of laboratory protocol for M. paratuberculosis culture from faeces. Diagnostic Laboratory, N.Y.S. College of Veterinary Medicine, Cornell University, Ithaca, NY, USA, Pp 8.

Sockett DC, TA Conrad, CB Thomas, MT Collins. 1992. Evaluation of four serological tests for bovine paratuberculosis. J Clin Microbiol 30, 1134-1139.

Soto JP, J Kruze, S Leiva. 2002ª . Comparación de tres métodos de diagnóstico de paratuberculosis bovina en rebaños lecheros infectados. Arch Med Vet 34, 265-273.

Soto JP, J Kruze, S Leiva. 2002 ${ }^{\mathrm{b}}$. Aislamiento de Mycobacterium avium subsp. paratuberculosis de fecas en rebaños lecheros infectados mediante el método de Cornell modificado. Arch Med Vet 34, 275-282.

Stabel JR. 1997. An improved method for cultivation of Mycobacterium paratuberculosis from bovine faecal samples and comparison to three other methods. J Vet Diagn Invest 9, 375-380.

Stabel JR. 1998. Jonhe's disease: a hidden threat. J Dairy Sci 81, 283-288.

Sweeney RW, RH Whitlock, CL Buckey, PA Spencer. 1995. Evaluation of a commercial enzyme-linked immunosorbent assay for the diagnosis of paratuberculosis in dairy cattle. J Vet Diagn Invest 7, 488-493.

Tavornpanich S, IA Gardner, RJ Anderson, SJ Shin, RH Whitlock, T Fyock, JM Adaska, RL Walker, SK Hietala. 2004. Evaluation of microbial culture of pooled fecal samples for detection of Mycobacterium avium subsp. paratuberculosis in large dairy herds. Am J Vet Res 65,1061-1070.

Van Schaik G, CH Kalis, G Benedictus, AA Dijkhuizen, RB Huine. 1996. Cost benefit analysis of vaccination against paratuberculosis in dairy cattle. Vet Rec 139, 624-627.

Van Schaik G, SM Stehman, YH Schukken. 2003. Pooled fecal-culture sampling for Mycobacterium avium subsp. paratuberculosis at different herd-sizes and prevalence. J Vet Diagn Invest 15, 233-241.

Van Schaik G, S Stehman, RH Jacobson, YH Schukken, SJ Shin, DH Lein. 2005. Cow-level evaluation of a kinetics ELISA with multiple cutoff values to detect fecal shedding of Mycobacterium avium subsp. paratuberculosis in New York State dairy cows. Prev Vet Med 72, 221-236.

Van Schaik G, M Pradenas, A Mella, J Kruze. 2007. Diagnostic validity and costs of pooled fecal samples and individual blood or fecal samples to determine the cow- and herd- status for Mycobacterium avium subsp. paratuberculosis. Prev Vet Med 82, 159-165.

Wells SJ, RH Whitlock, CJ Lindeman, T Fyock. 2002. Evaluation of bacterial culture of pooled fecal samples for detection of Mycobacterium paratuberculosis. Am J Vet Res 63, 1207-1211.

Wells SJ, SM Goddeen, CJ Lindeman, JE Collins. 2003. Evaluation of bacteriologic culture of individual and pooled fecal samples for detection of Mycobacterium paratuberculosis in dairy cattle herds. J Am Vet Med Ass 7, 1022-1025.

Whitlock RH, C Buergelt. 1996. Preclinical and clinical manifestations of paratuberculosis (including pathology). Vet Clin North Am Food Anim Pract 12, 345-356.

Whitlock RH, SJ Wells, RW Sweney, J Van Tiem. 2000. ELISA and faecal culture for sensitive and economic detection of Mycobacterium avium subsp. paratuberculosis infection in flocks of sheep. $J$ Clin Microbiol 38, 2550-2556.

Whittington RJ, S Fell, D Walker. 2000. Use of pooled fecal-culture for sensitive and economic detection of Mycobacterium avium subsp. paratuberculosis infection in flocks of sheep. J Clin Microbiol 38, 2550-2556.

Zamora J, J Kruze, C Schifferli. 1975. Paratuberculosis ovina. Primer caso descrito en Chile. Arch Med Vet 7,15-17. 